\title{
Reproductive factors and fatal hip fractures. A Norwegian prospective study of 63000 women
}

\author{
Bjarne K Jacobsen, Steinar Nilssen, Ivar Heuch, Gunnar Kvåle
}

\begin{abstract}
Study objective-The aim of the study was to investigate the impact of reproductive variables (age at menarche, menopause, first and last birth as well as parity, lactation, and abortions) on hip fracture mortality.

Design and setting-A prospective study in Norway with more than 60000 women followed up for 29 years. A total of 465 deaths as a result of hip fracture were recorded.

Main results-Statistically significant linear relations $(p \leqslant 0.02)$ were found between both age at menarche and length of reproductive period (defined as age at menopause to age at menarche) and the mortality of hip fractures in women aged less than 80. The death rate for women with a late menarche ( $\geqslant 17$ years) was twice that of the women with relatively early menarche ( $\leqslant 13$ years). Compared with women with less than 30 years between menopause and menarche, the mortality rate ratio in women with more than 38 reproductive years was 0.5 . We also found an inverse relation with age at first birth.

Conclusions-This study supports the hypothesis that an early menarche and a long reproductive period protect against hip fracture mortality. High age at first birth may also be protective.
\end{abstract}

Institute of

Community Medicine, University of Tromsø, Tromsø, N-9037

Tromsø, Norway

B K Jacobsen

Section for Medical Statistics, Department of Public Health and Primary Health Care, University of Bergen,

Bergen, Norway

$S$ Nilssen

Department of Mathematics, University of Bergen, Bergen, Norway I Heuch

Centre for

International Health, University of Bergen, Bergen, Norway G Kvåle

Correspondence to: Dr B K Jacobsen.

Accepted for publication 26 February 1998
(F Epidemiol Community Health 1998;52:645-650)

Hip fracture is one of the most serious effects of osteoporosis in terms of mortality, disability, and economic costs. Cooper and coworkers found that the relative five year survival rate was 0.82 , with most of the excess mortality seen during the first six months after the fracture. ${ }^{1}$ Hip fracture is also one of the most frequent osteoporotic fractures in advanced age. Therefore, risk factors for hip fractures have been studied extensively during the past two decades. ${ }^{2-4}$

A possible influence of reproductive history on the risk of hip fracture is suggested by the importance of oestrogen in reducing osteoporosis and fracture rates. ${ }^{25} \mathrm{~A}$ long period of exposure to endogenous oestrogen - that is, many years from menarche to menopausemight be expected to reduce the risk of hip fracture. However, neither age at menarche nor age at menopause have been consistently associated with hip fracture risk in previous studies, ${ }^{4-14}$ and it has been suggested that only very high age at menarche or menopause may have any effect on hip fracture risk. ${ }^{12}$
Similarly, it is at present not known whether parity has any impact on the risk of hip fracture. ${ }^{71012-17}$ Breast feeding, however, may, despite a possible reduced bone density because of extended lactation, ${ }^{18}$ reduce the long term risk of hip fracture according to some, but not all studies. ${ }^{4} 712131517$

Thus, the evidence for an effect of reproductive variables on hip fracture risk is not strong. In this study, we present the results from a 29 year follow up of a Norwegian cohort of more than 60000 women. The end point is mortality from hip fracture.

\section{Methods}

During 1956-59, information about reproductive factors was collected in personal interviews of women who participated in a screening programme for breast cancer in the three Norwegian counties of Vestfold, Nord-Trøndelag, and Aust-Agder. A total of 63090 women alive and aged 32-74 years at 1 January 1961 were included in this study. The information included age at menarche and menopause (if the woman was postmenopausal), number of fullterm pregnancies, age at first and last birth, duration of lactation, and the number of abortions as well as information about surgery on genital organs (for example, ovariectomy). In particular, the women were asked about the age when the menstruation started and stopped. This was recorded as age at menarche and menopause. For each delivery, the woman was asked to indicate how many months the child had been breast fed. The screening procedures are detailed elsewhere. ${ }^{19}$

Follow up started on 1 January 1961, when the unique personal registration number was introduced in Norway. During follow up from 1961 to 1989,27993 of the women included in the cohort died. Information on vital status and cause of death was obtained from files kept at the Central Bureau of Statistics (Statistics Norway), Oslo. A total of 465 women died of a hip fracture - that is, hip fracture was stated on the death certificate. Because of the routines of the Central Bureau of Statistics, it is not possible to say whether the fracture was the underlying cause of death or an associated cause. A fall was, however, reported in all but three of the cases. Thus, the hip fracture must have been important in the process leading to death in the great majority of the cases. No differentiation was made between cervical and trochanteric fractures.

Information on height and weight was available for 50101 of the 63090 women, derived from separate measurements made during the time period 1963-1975 as part of compulsory 
mass examination for tuberculosis. Body mass index was defined as weight/height ${ }^{2}$.

Relations between reproductive variables and hip fracture mortality were investigated by Poisson regression ${ }^{20}$ taking into account the number of person years at risk contributed by each woman in different age groups. Women who died of other causes than hip fractures were censored, as were all women alive at the end of follow up, 31 December 1989. Each analysis included all women with known values for the variables considered, and thus the total number of women differed somewhat between analyses. Maximum likelihood estimates of mortality rate ratios with $95 \%$ confidence intervals were calculated in a multiplicative model. Likelihood ratio tests for linear trend and departure from a linear trend were performed. The data file with aggregate information on the number of deaths because of hip fracture and person years was generated by the DATAB module in the EPICURE program package. ${ }^{21}$ The analyses were carried out by means of the AMFIT module.

As the effect of reproductive variables on hip fracture mortality may be influenced by the age of the women, we performed separate analyses in two age groups $50-79$ years and 80 years and above. With a cut off point of 79 years, enough cases remained in the first group to permit reliable statistical analyses. All analyses were adjusted for attained age (five years groups), county of residence and, as an indicator of social class, occupational group (own or husband's occupation).

\section{Results}

Table 1 gives the associations between demographic variables and hip fracture mortality in

Table 1 Hip fracture mortality and demographic variables; distribution of person years and mortality rate ratio (MRR) with $95 \%$ confidence intervals

\begin{tabular}{|c|c|c|c|}
\hline & $\begin{array}{l}\text { Person years } \\
(\times 1000)\end{array}$ & Deaths & $\operatorname{MRR}(95 \% C I)$ \\
\hline Total series & 1247.3 & 465 & \\
\hline \multicolumn{4}{|l|}{ Attained age } \\
\hline $50-74$ & 1035.2 & 63 & 1.00 \\
\hline $75-79$ & 117.3 & 103 & $14.42(10.54,19.73)$ \\
\hline $80-84$ & 63.3 & 119 & $30.90(22.77,41.94)$ \\
\hline $85-89$ & 24.9 & 123 & $81.06(59.83,109.8)$ \\
\hline $90-99$ & 6.6 & 57 & $142.1(99.28,203.3)$ \\
\hline $\mathrm{p}$ value for heterogeneity & & & $<0.001$ \\
\hline \multicolumn{4}{|l|}{ Birth cohort ${ }^{\star}$} \\
\hline $1885-1889$ & 20.8 & 42 & 1.00 \\
\hline $1890-1899$ & 176.3 & 238 & $1.11(0.80,1.54)$ \\
\hline $1900-1909$ & 368.7 & 147 & $0.97(0.68,1.38)$ \\
\hline $1910-1929$ & 681.5 & 38 & $1.00(0.60,1.68)$ \\
\hline$p$ value for heterogeneity & & & 0.67 \\
\hline \multicolumn{4}{|l|}{$\begin{array}{l}\text { p value ior neterogenerty } \\
\text { Place of residencet }\end{array}$} \\
\hline Urban & 263.3 & 115 & 1.00 \\
\hline Rural & 984.0 & 350 & $0.82(0.67,1.02)$ \\
\hline $\mathrm{p}$ value for heterogeneity & & & 0.07 \\
\hline \multicolumn{4}{|l|}{ County } \\
\hline Nord-Trøndelag & 424.8 & 134 & 1.00 \\
\hline Aust-Agder & 273.2 & 74 & $0.75(0.56,0.99)$ \\
\hline Vestfold & 549.4 & 257 & $1.55(1.26,1.91)$ \\
\hline $\mathrm{p}$ value for heterogeneity & & & $<0.001$ \\
\hline \multicolumn{4}{|l|}{ Occupational category $† \ddagger$} \\
\hline Professional, private enterprise & 196.1 & 72 & 1.00 \\
\hline Clerical work & 151.0 & 48 & $0.88(0.61,1.27)$ \\
\hline Fishing, ship officers, crew & 108.8 & 36 & $0.95(0.64,1.42)$ \\
\hline Farm and forestry work & 275.5 & 93 & $0.74(0.54,1.01)$ \\
\hline Industrial work & 152.1 & 63 & $1.37(0.98,1.92)$ \\
\hline Domestic and other work & 218.8 & 79 & $0.97(0.71,1.34)$ \\
\hline Not specified & 145.0 & 74 & $1.00(0.72,1.39)$ \\
\hline $\mathrm{p}$ value for heterogeneity & & & 0.02 \\
\hline
\end{tabular}

*Adjusted for attained age in one year intervals. †Adjusted for attained age in five year intervals $\ddagger$ Own or husband's occupation. Adjusted for attained age in five year intervals. this cohort. The youngest and oldest women who died after a hip fracture were 50 and 99 years old at death, respectively. As expected, a very strong positive relation was seen with age. Women who lived in rural areas at the time of screening had lower risk than women in urban areas. A relatively high hip fracture mortality was observed in the county of Vestfold and a low mortality in Aust-Agder, both counties in the southern part of Norway. This difference remained after adjustment for urban/rural place of residence (data not shown). Women with own or husband's occupation within industrial work had a relatively high hip fracture mortality, whereas women in the occupational group "farm and forestry work" had a relatively low hip fracture mortality. Thus, we have adjusted for age, county, and occupational group in our analyses.

Table 2 shows the relations between age at menarche and menopause, the number of years between age at menarche and menopause (reproductive period) and hip fracture mortality. In the 50-79 year age group, a statistically significant inverse relation was seen between the number of reproductive years and hip fracture mortality. Compared with women with less than 30 years between menopause and menarche, the mortality rate ratio in women with more than 38 reproductive years was 0.51 . This effect was reflected in associations between both age at menarche (where a statistically significant positive relation was seen) and age at menopause and hip fracture mortality. In the older age group, no relation with hip fracture mortality was observed.

In view of the grouping of values of age at menopause and reproductive period, it is important to carry out an accurate adjustment for current age. To confirm that the relations in women aged $50-79$ years were not caused by confounding by age, separate analyses were carried out with adjustment for age in one year instead of five year intervals. This did not, however, influence the relative risk estimates (results not shown).

Relations between reproductive period and hip fracture mortality could have been biased by women with a surgical menopause, who may have a relatively short reproductive period. Thus, separate analyses were also carried out excluding 4131 women who indicated at screening that they had had operations on the ovaries, hysterectomy, unspecified operation of the womb or radiography or radium treatment of the genital organs. This did not, however, weaken the relation between reproductive period and hip fracture mortality ( $\mathrm{p}$ value for trend $=0.008$ in women aged $50-79$ years).

Table 3 shows the relations between variables connected to childbearing and hip fracture mortality. No associations were found between parity and hip fracture mortality, but a lower hip fracture mortality was indicated in women with high age at first birth. A long duration of lactation was not statistically significantly associated with hip fracture mortality. No relation was found between the number of abortions reported and hip fracture mortality. 
Table 2 Hip fracture mortality and age at menarche, age at menopause and reproductive period; distribution of person years and mortality rate ratio (MRR) with $95 \%$ confidence intervals, by age group

\begin{tabular}{|c|c|c|c|c|c|c|c|c|}
\hline & & \multirow{3}{*}{$\begin{array}{l}\text { Person } \\
\text { years } \\
(\times 1000)\end{array}$} & \multirow{2}{*}{\multicolumn{2}{|c|}{ Total }} & \multicolumn{4}{|l|}{ Age (y) } \\
\hline & & & & & \multicolumn{2}{|l|}{$50-79$} & \multicolumn{2}{|l|}{$\geqslant 80$} \\
\hline & & & Deaths & $\operatorname{MRR}(95 \% C I)$ & Deaths & $M R R(95 \% C I)$ & Deaths & $\operatorname{MRR}(95 \% C I)$ \\
\hline \multirow[t]{5}{*}{ Age at menarche ${ }^{\star}$} & $\leqslant 13$ & 345.0 & 90 & 1.00 & 29 & 1.00 & 61 & 1.00 \\
\hline & 14 & 393.1 & 137 & $1.06(0.81,1.38)$ & 46 & $1.25(0.79,1.99)$ & 91 & $0.96(0.69,1.33)$ \\
\hline & 15 & 274.9 & 121 & $1.14(0.87,1.50)$ & 46 & $1.62(1.01,2.57)$ & 75 & $0.93(0.66,1.31)$ \\
\hline & 16 & 126.4 & 57 & $1.04(0.75,1.45)$ & 23 & $1.61(0.93,2.78)$ & 34 & $0.81(0.53,1.23)$ \\
\hline & $\geqslant 17$ & 74.3 & 44 & $1.12(0.78,1.60)$ & 18 & $2.02(1.12,3.64)$ & 26 & $0.80(0.51,1.27)$ \\
\hline $\mathrm{p}$ value for linear trend & & & & 0.54 & & 0.01 & & 0.22 \\
\hline \multirow{5}{*}{ Age at menopause } & $\leqslant 43$ & 62.9 & 60 & 1.00 & 21 & 1.00 & 39 & 1.00 \\
\hline & $44-46$ & 66.5 & 48 & $0.72(0.49,1.05)$ & 17 & $0.74(0.39,1.41)$ & 31 & $0.71(0.44,1.13)$ \\
\hline & $47-49$ & 114.2 & 78 & $0.66(0.47,0.92)$ & 25 & $0.62(0.34,1.10)$ & 53 & $0.68(0.45,1.03)$ \\
\hline & $50-52$ & 141.6 & 144 & $0.83(0.61,1.12)$ & 36 & $0.69(0.40,1.18)$ & 108 & $0.90(0.62,1.30)$ \\
\hline & $\geqslant 53$ & 49.9 & 61 & $0.84(0.59,1.20)$ & 11 & $0.58(0.28,1.21)$ & 50 & $0.95(0.62,1.44)$ \\
\hline $\mathrm{p}$ value for linear trend & & & & 0.77 & & 0.15 & & 0.58 \\
\hline \multirow[t]{5}{*}{ Reproductive period (y) $\ddagger$} & $\leqslant 29$ & 71.7 & 68 & 1.00 & 26 & 1.00 & 42 & 1.00 \\
\hline & $30-32$ & 74.0 & 61 & $0.80(0.56,1.13)$ & 20 & $0.71(0.40,1.28)$ & 41 & $0.85(0.55,1.31)$ \\
\hline & $33-35$ & 126.5 & 93 & $0.69(0.50,0.94)$ & 29 & $0.59(0.35,1.00)$ & 64 & $0.75(0.51,1.10)$ \\
\hline & $36-38$ & 109.5 & 110 & $0.85(0.63,1.15)$ & 23 & $0.54(0.31,0.94)$ & 87 & $1.03(0.71,1.49)$ \\
\hline & $\geqslant 39$ & 43.5 & 47 & $0.81(0.56,1.18)$ & 9 & $0.51(0.24,1.09)$ & 38 & $0.98(0.63,1.52)$ \\
\hline $\mathrm{p}$ value for linear trend & & & & 0.41 & & 0.02 & & 0.62 \\
\hline
\end{tabular}

^Among women with known age at menarche, adjusted for attained age, county, and occupational group. $\dagger$ Among women with known age at menopause, adjusted for attained age, county, and occupational group. ¥Among women with known age at menarche and menopause, adjusted for attained age, county, and occupational group.

In the subgroup of women with information about height and weight, a highly significant inverse relation $(\mathrm{p}<0.001)$ was found between body mass index and hip fracture mortality. The mortality of hip fracture for obese women (body mass index $>30 \mathrm{~kg} / \mathrm{m}^{2}$ ) was $33 \%$ of that for lean women (body mass index $<20 \mathrm{~kg} / \mathrm{m}^{2}$ ). This association was also seen in the 50-79 years age group ( $\mathrm{p}$ value for linear trend $=0.008)$. The major difference in mortality risk (approximately 60\%) seemed to be between that of lean women compared with women with body mass index $\geqslant 20 \mathrm{~kg} / \mathrm{m}^{2}$.

The negative relation between number of reproductive years and hip fracture in women aged 50-79 years was upheld after adjustment for body mass index ( $p$ value for linear trend=0.02). Similarly, the negative relation between age at first birth and hip fracture mortality was somewhat strengthened ( $p$ value for linear trend $\leqslant 0.05$ in both age groups). The mortality rate ratio (MRR) for women with age at first birth $\geqslant 35$ years was $0.46 \quad(95 \%$ confidence intervals $0.26,0.83$ ) compared with women with age at first birth $\leqslant 24$ years; nearly identical MRRs were found in both age groups.

After adjustment for body mass index, the negative association between duration of lactation and hip fracture mortality was slightly stronger than that displayed in table 3 for women aged 50-79 years $(M R R=0.41$, $95 \%$ confidence intervals $0.16,1.10$, when

Table 3 Hip fracture mortality and parity, age at first and last birth, lactation and abortions; distribution of person years and mortality rate ratio (MRR) with $95 \%$ confidence intervals, by age group

\begin{tabular}{|c|c|c|c|c|c|c|c|c|}
\hline & & \multirow{3}{*}{$\begin{array}{l}\text { Person } \\
\text { years } \\
(\times 1000)\end{array}$} & \multirow{2}{*}{\multicolumn{2}{|c|}{ Total }} & \multicolumn{4}{|l|}{ Age (y) } \\
\hline & & & & & \multicolumn{2}{|l|}{$50-79$} & \multicolumn{2}{|l|}{$\geqslant 80$} \\
\hline & & & Deaths & $\operatorname{MRR}(95 \% C I)$ & Deaths & $M R R(95 \% C I)$ & Deaths & $M R R(95 \% C I)$ \\
\hline \multirow[t]{4}{*}{ Parity ${ }^{\star}$} & 0 & 226.8 & 111 & 1.00 & 37 & 1.00 & 74 & 1.00 \\
\hline & $1-2$ & 529.4 & 156 & $0.88(0.69,1.13)$ & 56 & $0.81(0.53,1.24)$ & 100 & $0.93(0.69,1.27)$ \\
\hline & $3-4$ & 344.9 & 116 & $0.88(0.68,1.16)$ & 45 & $0.97(0.62,1.51)$ & 71 & $0.84(0.60,1.18)$ \\
\hline & $\geqslant 5$ & 120.5 & 73 & $1.02(0.75,1.39)$ & 24 & $1.22(0.72,2.07)$ & 49 & $0.95(0.65,1.37)$ \\
\hline $\mathrm{p}$ value for linear trend & & & & 0.98 & & 0.42 & & 0.55 \\
\hline \multirow[t]{4}{*}{ Age at first birth $(y) \dagger$} & $\leqslant 24$ & 367.3 & 142 & 1.00 & 53 & 1.00 & 89 & 1.00 \\
\hline & $25-29$ & 345.1 & 118 & $1.03(0.80,1.32)$ & 40 & $0.89(0.59,1.36)$ & 78 & $1.11(0.81,1.52)$ \\
\hline & $30-34$ & 164.9 & 45 & $0.77(0.54,1.09)$ & 20 & $0.90(0.52,1.53)$ & 25 & $0.69(0.43,1.09)$ \\
\hline & $\geqslant 35$ & 71.5 & 19 & $0.57(0.35,0.93)$ & 7 & $0.58(0.25,1.31)$ & 12 & $0.56(0.30,1.05)$ \\
\hline $\mathrm{p}$ value for linear trend & & & & 0.02 & & 0.24 & & 0.04 \\
\hline \multirow{4}{*}{ Age at last birth (y) $\ddagger$} & $\leqslant 29$ & 272.7 & 92 & 1.00 & 39 & 1.00 & 53 & 1.00 \\
\hline & $30-34$ & 297.8 & 90 & $0.89(0.66,1.20)$ & 28 & $0.63(0.38,1.03)$ & 62 & $1.09(0.75,1.60)$ \\
\hline & $35-39$ & 254.4 & 85 & $0.79(0.57,1.08)$ & 27 & $0.52(0.31,0.88)$ & 58 & $1.02(0.68,1.52)$ \\
\hline & $\geqslant 40$ & 124.0 & 57 & $0.76(0.53,1.10)$ & 26 & $0.83(0.48,1.45)$ & 31 & $0.71(0.44,1.16)$ \\
\hline $\mathrm{p}$ value for linear trend & & & & 0.10 & & 0.27 & & 0.22 \\
\hline \multirow[t]{5}{*}{ Total lactation (months) $\$} & 0 & 77.0 & 27 & 1.00 & 11 & 1.00 & 16 & 1.00 \\
\hline & $1-9$ & 314.0 & 72 & $0.70(0.45,1.10)$ & 33 & $0.81(0.41,1.60)$ & 39 & $0.64(0.36,1.15)$ \\
\hline & $10-19$ & 255.2 & 79 & $0.76(0.49,1.19)$ & 27 & $0.69(0.34,1.41)$ & 52 & $0.81(0.46,1.43)$ \\
\hline & $20-29$ & 142.8 & 53 & $0.78(0.48,1.28)$ & 19 & $0.72(0.33,1.57)$ & 34 & $0.83(0.44,1.55)$ \\
\hline & $\geqslant 30$ & 121.4 & 63 & $0.80(0.48,1.35)$ & 17 & $0.59(0.25,1.37)$ & 46 & $0.96(0.49,1.86)$ \\
\hline $\mathrm{p}$ value for linear trend & & & & 0.88 & & 0.24 & & 0.45 \\
\hline \multirow[t]{3}{*}{ Abortions $\uparrow$} & 0 & 935.9 & 349 & 1.00 & 128 & 1.00 & 221 & 1.00 \\
\hline & 1 & 175.1 & 58 & $0.98(0.74,1.30)$ & 21 & $0.90(0.56,1.44)$ & 37 & $1.03(0.72,1.47)$ \\
\hline & $\geqslant 2$ & 70.0 & 26 & $0.96(0.64,1.45)$ & 9 & $0.90(0.45,1.78)$ & 17 & $1.00(0.60,1.66)$ \\
\hline $\mathrm{p}$ value for linear trend & & & & 0.82 & & 0.63 & & 0.93 \\
\hline
\end{tabular}

^Among women with known parity, adjusted for attained age, county, and occupational group. †Among parous women with known parity and age at first birth, adjusted for attained age, county, occupational group, and parity. ‡Among parous women with known parity and age at last birth, adjusted for attained age, county, occupational group, and parity. \$Among parous women with known parity and total lactation, adjusted for attained age, county, occupational group, and parity. IAmong women with known parity and number of abortions, adjusted for attained age, county, occupational group, and parity. 
comparing women with $\geqslant 30$ months with women who reported no lactation, $\mathrm{p}$ value for linear trend $=0.10)$. No interaction with parity was indicated in the relation between lactation and hip fracture mortality (results not shown).

\section{Discussion}

In this 29 year follow up of more than 60000 women, we found a protective effect of an early menarche, a long reproductive period, and a high age at first birth on the risk of hip fracture mortality.

There is no reason to believe that any of the women included as cases have not sustained a hip fracture. However, some women who die after a hip fracture may not have this diagnosis stated on the death certificate. Meyer and coworkers $^{22}$ have reported a comparison between the incidence and mortality of hip fractures in Norway in 1979. The number of persons who had a diagnosis of hip fracture on their death certificate was about one tenth of the total number of fractures (603 and 5920 subjects, respectively), which is below the expected $12-20 \%$ one year excess mortality after a hip fracture. ${ }^{1}$ Still, the strength of the relations between reproductive factors and hip fracture mortality should be affected only if the reproductive history influences the probability that the fracture is included as a cause on the death certificate.

Parity or age at menarche or menopause are unlikely to influence the decision whether the hip fracture should be reported, as this information is not normally available to the physician completing the death certificate. However, if there is a relation between these variables and the total number of diagnoses reported on the death certificate, this may influence the likelihood that the hip fracture is included. A person with many serious or concomitant diseases might have lower probability that the hip fracture is reported. To explain the inverse relation between the number of reproductive years and hip fracture mortality in this way, substantially fewer diagnoses have to be reported in women with a long reproductive period than in women with a short period. This was not the case. In death certificates from women aged 50-79 years with $<30$ years between menarche and menopause, the mean number of diagnoses was 1.80 compared with 1.74 in women with a long reproductive period ( $>38$ years) (unpublished observations).

Most women who sustain a hip fracture survive. ${ }^{1}$ Thus, during the 29 years of follow up, many hip fractures must have occurred in the cohort that were not included as cases in our study. This may influence the extent to which our results are valid for reproductive factors regarded as risk factors for hip fracture incidence. Possible associations between reproductive factors and hip fracture fatality cannot be excluded, although we are not aware of published results indicating associations between, for example, the number of reproductive years and hip fracture survival.

Our data do not, however, indicate that there is an inverse association between length of
KEY POINTS

- Out of a total of 60000 women followed up for 29 years, 465 women died after a hip fracture.

- In women aged 79 and less, late menarche and a short reproductive period increase hip fracture mortality.

- The most likely explanation to this finding is that long duration of endogenous oestrogens reduces osteoporosis.

- High age at first birth (particularly > 34 years) reduces hip fracture mortality.

- Reproductive factors are important for hip fracture mortality.

reproductive period and total mortality. Such a relation would suggest that this variable is related to general health and thereby to survival, which could explain our result. In women aged 50-79 years, no association was observed between length of reproductive period and total mortality (MRR comparing $>$ 38 years with < 30 years was 1.07 (95\% CI: $0.98,1.16, \mathrm{p}$ value for linear trend=0.4). For age at menarche, a weak inverse relation was found ( $p$ value for trend=0.05) (unpublished observations), in contrast with what might be expected if the positive associations between age at menarche and hip fracture mortality should be explained by effects of age at menarche on general health.

The data collected at the screening on parity and age at first and last delivery must be regarded as highly reliable. Information concerning abortions and age at menarche and menopause is more subject to random error, which may weaken possible relations.

The analyses involving age at menopause and length of the reproductive period did not include women who were pre-menopausal at time of screening. Thus, in the younger age groups, women with an early menopause are over-represented in the data set analysed. This does not, however, introduce any bias in the evaluation of associations based on regression analyses, with age at menopause or length of the reproductive period as independent variables. This is because the regression model for prospective studies describes death rates conditional on the particular values of the exposure variables. The actual distribution of exposure values is irrelevant in this connection.

For some exposure variables, such as parity and age at first and last birth, a minor bias is introduced by the reliance on possibly incomplete information collected at screening 2-5 years before the start of follow up. Some women may have given birth to children after the screening took place. In general, this will lead to observed relations that are slightly weaker than the true associations. This bias can therefore not explain the inverse relation found between age at first birth and hip fracture mortality.

Oestrogen, both endogenous ${ }^{23}$ and exogenous, ${ }^{2524}$ protects against osteoporosis. Our main results are consistent with the concept that a relatively long exposure to 
endogenous oestrogen reduces the hip fracture mortality through the well established positive relation between oestrogen and bone mass. ${ }^{23} 24$ The positive relation with age at menarche and inverse relations with age at menopause and the number of reproductive years all point in this direction. An effect of reproductive variables on the risk of falling, the other main risk factor for a hip fracture, may remain speculative, although it has been shown that exogenous oestrogen may improve postural balance in elderly women. ${ }^{25}$

We found an inverse relation between the length of reproductive period and hip fracture mortality. Our results thus support the findings of the MEDOS Study with 2086 cases,${ }^{13}$ and are consistent with the positive correlation found between number of reproductive years and bone density of the hip as well as the wrist, radius, and spine. ${ }^{26}$

The number of reproductive years is calculated as the difference between age at menopause and age at menarche. It is noteworthy that, at least in the group of women aged 50-79 years, a stronger effect is found for age at menarche than for age at menopause $(\mathrm{MMR}=1.15 \vee 1.05$ per year). Although we would not interpret this too far, it may indicate that hormonal factors associated with the teen years may be of greater importance than those associated with the menopause. Possibly, bone mineralisation may be stimulated earlier in women with early menarche, thereby obtaining a higher peak bone mass. ${ }^{24}$ Recently, it has been reported that in postmenopausal women, age at menarche is positively and age at menopause inversely associated with low bone mineral density. ${ }^{27}$

A reduced impact of the length of the reproductive period was observed with advancing age. This is consistent with findings of Gärdsell and coworkers, ${ }^{28}$ and may simply reflect the longer time since exposure to high levels of endogenous oestrogen. Our finding agrees with the observation that the female excess morbidity of osteoporotic fractures levels off at about 75 years of age, indicating that the duration of the menopause effect is approximately 25 years. ${ }^{29}$ Furthermore, with increasing incidence of a disease (a hip fracture), the relative importance of each risk factor can be attenuated. In old women the bone mass is generally low, and other variables (for example, the tendency to fall) may become more important as predictors for sustaining a hip fracture.

Our results suggest a relatively strong inverse relation between age at first birth and hip fracture mortality, a relation found to be upheld after adjustments for body mass index. This association was independent of age group (50-79 or $\geqslant 80$ years). It has previously been reported that a first pregnancy before age 20 is associated with lower bone mass density, ${ }^{24}$ but case-control studies have shown no relation, or a positive relation, between age at first birth and hip fracture risk. ${ }^{72} 17$

The lack of any relation between parity and hip fracture mortality is consistent with combined results from several previous studies. ${ }^{7}{ }^{10-17}$ The possible effects of multipar- ity on hip fracture risk may simply not last into the postmenopausal ages when the vast majority of hip fractures occur, or such effects may be diverse and contradictory. We did not find a significant relation between lactation and hip fracture mortality, although an inverse relation was suggested as in some other studies. ${ }^{72}$ In still other studies ${ }^{4131517}$ no significant relation was found.

A high body mass index is well established as a protective factor for hip fractures. ${ }^{2}{ }^{4}$ The strong association seen in our study supports the basic validity of using mortality of hip fractures as the end point in our analyses. We do, however, acknowledge that the adjustment for body mass index is less than optimal as we have information about body mass index for only $82 \%$ of the women and the information was collected during follow up. However, body mass index does not seem to be an important confounder. The correlation between body mass index and reproductive factors is low in this population. ${ }^{19}$ Furthermore, adjustment for the body mass index did not weaken but, if anything, strengthened the relation with number of reproductive years, age at first birth or with extended lactation.

We do not believe that oestrogen replacement therapy has influenced our findings to any significant degree, as such therapy was rather uncommon for women in this cohort. Oestrogen replacement therapy for perimenopausal complaints (for example, heat flushes) was very seldom used in Norway in the late 1950 s. It is also rather unlikely that such therapy was of any significance during follow up. Such treatment has until recently not been common in Norway. Even if all use of non-contraceptive oestrogen in Norway in 1979 was attributed to women in the age group 45-54 years (women in the climacteric age), only $9 \%$ of the women would be users. ${ }^{30}$ In 1979 the youngest women included in this cohort were 50 years old and $78 \%$ of the cohort was above 58 years old. ${ }^{19}$

High physical activity is negatively related to hip fracture risk. ${ }^{41131}$ To explain our results by this confounder, we have to assume a relatively strong positive association between physical activity and reproductive period or age at first delivery, even after adjustment for age group, county, and occupational group (which to some extent may be a proxy for physical activity).

Other possible confounders in our study are cigarette smoking and alcohol and coffee drinking, habits that may be risk factors for hip fractures. $^{2432}$ We have no information about smoking, alcohol or coffee consumption habits of the individual woman. However, from what is known about smoking habits in the birth cohorts considered in this study, a large majority of the women were non-smokers. ${ }^{33}$ From the national data presented by Rønneberg and coworkers, ${ }^{33}$ we have estimated that in the birth cohorts included in our study, more than $70 \%$ were lifelong non-smokers. In age groups where the majority of the women were postmenopausal at screening (born before 1911) this proportion was considerably higher, 
approximately $82 \%$. This is the relevant age group as only postmenopausal women contributed to the analysis of reproductive period as risk factor for hip fracture.

Confounding by alcohol drinking is even less likely because in 1973 less than $2 \%$ of the Norwegian women aged 18 and more had a daily consumption of alcoholic beverages corresponding to more than $20 \mathrm{ml}$ pure alcohol. ${ }^{34}$ Alcohol consumption and smoking prevalence among women included in this study living predominantly in rural parts of the country were probably even lower. Thus, confounding by alcohol drinking or cigarette smoking is not likely to be of major importance for our results.

Coffee drinking is a common habit in Norway. ${ }^{35}$ A weak positive relation between coffee consumption and parity has been found in middle aged women in Norway. ${ }^{36}$ However, there must be a rather strong association between coffee consumption and reproductive variables to influence our findings notably.

In summary, in this large cohort of Norwegian women, we found a statistically significant protective effect of an early menarche and a long reproductive period on the mortality of hip fractures in women aged less than 80 . There was also evidence for a protective effect of high age at first birth. However, in view of the sampling errors associated with our estimates, these relations should be studied further in other prospective studies with hip fracture incidence as the end point.

Funding: this study received funding from the Norwegian Cancer Society for financial support.

Conflicts of interest: none.

1 Cooper C, Atkinson EJ, Jacobsen SJ, et al. Population-based study of survival after osteoporotic fractures. $A m \mathcal{F}$ Epidemiol 1993;137:1001-5.

2 Cummings SR, Kelsey JL, Nevitt MC, et al. Epidemiology of osteoporosis and osteoporotic fractures. Epidemiol Rev of osteoporosis and

3 Cooper C. Epidemiology and public health impact of osteoporosis. Baillieres Clin Rheumatol 1993;7:459-77.

4 Cummings SR, Nevitt MC, Browner WS, et al. Risk factors for hip fracture in white women. $N$ Engl $f \mathrm{Med}$ 1995;332:767-73.

5 Barlow DH. HRT and osteoporosis. Baillieres Clin Rheumatol 1993; 7:535-48.

6 Kiel DP, Felson DT, Anderson JJ, et al. Hip fracture and the use of estrogens in postmenopausal women. The Framingham Study. N Engl f Med 1987;317:1169-74.

7 Kreiger N, Kelsey JL, Holford TR, et al. An epidemiologic study of hip fracture in postmenopausal women. Am F EPidemiol 1982;116:141-8.

8 Hutchinson TA, Polansky SM, Feinstein AR. Postmenopausal oestrogens protect against fractures of hip and menopausal oestrogens protect against fractures of hip and
distal radius. A case-control study. Lancet 1979;ii:705-9.

9 Paganini-Hill A, Ross RK, Gerkins VR, et al. Menopausal estrogen therapy and hip fractures. Ann Intern Med 1981;95:28-31.
10 Paganini-Hill A, Chao A, Ross RK, et al. Exercise and other factors in the prevention of hip fracture: The Leisure World Study. Epidemiology 1991;2:16-25.

11 Cooper C, Barker DJP, Wickham C. Physical activity, muscle strength, and calcium intake in fracture of the proximal femur in Britain. BMF 1988;297:1443-6.

12 Cumming RG, Klineberg RJ. Breastfeeding and other reproductive factors and the risk of hip fractures in elderly women. Int F Epidemiol 1993;22:684-91.

13 Johnell O, Gullberg B, Kanis JA, et al. Risk factors for hip fracture in European women. The MEDOS Study. 7 Bone Miner Res 1995; 10:1802-15.

14 Parazzini F, Tavani A, Ricci E, et al. Menstrual and reproductive factors and hip fracture in post menopausal women. Maturitas 1996;24:191-6.

15 Alderman BW, Weiss NS, Daling JR, et al. Reproductive history and postmenopausal risk of hip and forearm fracture. Am 7 Epidemiol 1986;124:262-7.

16 Wyshak G. Hip fracture in elderly women and reproductive history. F Gerontal 1981;36:424-7.

17 Hoffmann S, Grisso JA, Kelsey JL, et al. Parity, lactation and hip fracture. Osteoporosis Int 1993;3:171-6.

18 Sowers $M$, Corton G, Shapiro B, et al. Changes in bone density with lactation. $\mathcal{F} A M A$ 1993;269:3130-5.

19 Kvåle G. Reproductive factors and risk of cancers of the breast and genital organs. A prospective study of Norwegian women. [Dr med thesis.] Bergen: University of Bergen, 1989.

20 Breslow NE, Day NE. Statistical methods in cancer research. Vol. 2. The design and analysis of cohort studies. Lyon: IARC, 1987:119-76.

21 Preston DL, Lubin JH, Pierce DA, et al. Epicure user's guide. Seattle: Hirosoft International Corporation, 1993.

22 Meyer HE, Tverdal Aa, Falch JA. Body height, body mass index, and fatal hip fractures: 16 years follow-up of 674,000 Norwegian women and men. Epidemiology 1995;6: 299-305.

23 Cauley JA, Gutai JP, Sandler RB, et al. The relationship of endogenous estrogen to bone density and bone area in normal postmenopausal women. Am f Epidemiol 1986;124: $752-61$

24 Sowers MR, Galuska DA. Epidemiology of bone mass in premenopausal women. Epidemiol Rev 1993;15:374-98.

25 Naessen T, Lindmark B, Larsen H-C. Better postural balance in elderly women receiving estrogens. Am 7 Obstet Gynecol 1997; 177:412-16.

26 Kritz-Silverstein D, Barrett-Connor E. Early menopause, number of reproductive years, and bone mineral density in postmenopausal women. Am F Public Health 1993;83:983-8.

27 Parazzini F, Bidoli E, Franceschi S, et al. Menopause, menstrual and reproductive history, and bone density in northern Italy. F Epidemiol Community Health 1996;50:519-23.

28 Gärdsell $\mathrm{P}$, Johnell $\mathrm{O}$, Nilsson $\mathrm{BE}$. The impact of meno-pausal age on future fragilty fracture risk. $\mathcal{F}$ Bone Miner Res 1991;6:429-33.

29 Kanis JA, Pitt FA. Epidemiology of osteoporosis. Bone 1992;13 (suppl 1):S7-15.

30 Bergsjø P. Comments on the use of oestrogens 1979-83. In: Øydvin K, ed. Drug consumption in Norway. Oslo: Norsk Medisinaldepot, 1984:114-5.

31 Coupland C, Wood D, Cooper C. Physical inactivity is an independent risk factor for hip fracture in the elderly. $\mathcal{F}$ Epidemiol Community Health 1993;47:441-3.

32 Hernandez-Avila M, Colditz GA, Stampfer MJ, et al. Caffeine, moderate alcohol intake, and risk of fractures of the hip and forearm in middle-aged women. Am $\mathcal{F}$ Clin Nutr 1991;54:157-63.

33 Rønneberg A, Lund KE, Hafstad A. Lifetime smoking habts among Norwegian men and women born between 1890 and 1974. Int F Epidemiol 1994;23:267-76.

34 Nordlund S. Data om alkoholspørsmàl. Tabellarisk oversikt over resultater fra intervjuundersøkelser 1956-1973 (in Norwegian). Oslo: Statens Institutt for Alkoholforskning, 1977.

35 Jacobsen BK, Bjelke E, Kvåle G, et al. Coffee drinking, mortality and cancer incidence: Results from a Norwegian prospective study. F Natl Cancer Inst 1986;76:823-31.

36 Jacobsen BK. Relationships between childbearing and some food and alcohol habits. The Nordland Health Study. Eur 7 Epidemiol 1996;12:327-30. 